\title{
The Impact of Working Beyond Traditional Retirement Ages on Mental Health: Implications for Public Health and Welfare Policy
}

\author{
Will Maimaris, BM Bchir, ${ }^{1}$ \\ Helen Hogan, MSc MBBS, ${ }^{1}$ \\ Karen Lock, $\mathrm{PhD}^{1}$
}

\begin{abstract}
Background: Many people now want or need to work longer due to increased life expectancy. In some countries statutory retirement ages deny older people free access to the labour market. It has been hypothesised that exclusion from employment may have negative effects on the mental health of older people. The global financial crisis has forced some countries to propose increasing the retirement age but the implications of this for population health are unclear. This paper reviews the evidence for the mental health impacts of working beyond retirement, and discusses the implications for future public health and welfare policy.

Methods: A systematic literature review was conducted of studies that examined the effect of working or volunteering beyond traditional retirement ages on mental health outcomes.

Results: Of the ten studies that met the inclusion criteria, none showed a negative impact of working beyond retirement age on mental health. Four studies showed that post-retirement working has a statistically significant positive effect on a range of mental health outcomes.

Discussion: This review suggests that working beyond traditional retirement ages may be beneficial for mental health in some populations. The mechanisms by which this occurs are complex but are likely to be mediated by the maintenance of productive societal roles, continued income and social support. The benefits of post-retirement employment are unlikely to be universal as such factors will have varying effects depending on individual lifestyle, self-esteem and socioeconomic status. Although our research shows that allowing older people free access to the employment market may have important health benefits, flexible retirement strategies are needed to ensure that any national policy to increase statutory retirement age does not increase health and social inequalities in the elderly.
\end{abstract}

\footnotetext{
${ }^{1}$ Faculty of Public Health and Policy, London School of Hygiene and Tropical Medicine.

Corresponding Author Contact Information: Will Maimaris at willmaimaris@yahoo.com; Faculty of Public Health and Policy, London School of Hygiene and Tropical Medicine, London, UK.
} 
Key words: Retirement, volunteerism, employment status, mental health, social policy, elderly

Recommended Citation: Maimaris W, Hogan H, Lock K. The impact of working beyond traditional retirement ages on mental health: Implications for public health and welfare policy. Public Health Reviews. 2010;32:532-48.

\section{INTRODUCTION}

People in almost all industrialised countries are living longer than ever before. Average life expectancy for people aged 65 has increased by about a third in Western Europe since 1970. However, although people tend to live longer, they do not always do so in good health. Mental health problems cause significant morbidity and mortality in the expanding elderly population. Worldwide it is estimated that mental disorders account for 12 percent of the global disease burden measured in terms of disabilityadjusted life years (DALYs). ${ }^{1}$ A review of studies on Caucasian populations found that the prevalence of depressive symptoms in elderly people ranged from 7.2 percent to 49 percent and the prevalence of major depression ranged from 0.9 percent to 9.4 percent. $^{2}$ In terms of mortality, suicide is the 11th leading cause of death in the United States, with approximately 5,000 of the 30,000 deaths from suicide per year occurring in the elderly population. ${ }^{3}$ Suicide in older people is linked to existing mental health problems in the majority of cases. ${ }^{4}$ In addition to the high levels of personal distress caused by poor mental health in the elderly, there are also considerable economic implications. Poor mental health increases the burden on health services through increased hospital admissions and physician visits and through the cost of the widespread prescription of antidepressant drugs. ${ }^{5}$ There is also growing concern about the increasing financial burden that ageing populations, especially those with poor health, pose to welfare states. ${ }^{6}$

It has been suggested that retirement may be an important social factor contributing to poor mental health in older people. ${ }^{7}$ It is hypothesised that the loss of responsibility, loss of role and loss of social contact following retirement can lead to depression. ${ }^{8}$ Excluding older people from the labour market may, therefore, have implications for the burden of mental illness. Improved physical health and longer life expectancy mean that many older people now wish to work beyond traditional retirement ages. However, in many countries including the United Kingdom, France and the Netherlands, employers are legally allowed to terminate the employment of an older 
employee when they reach the state mandated retirement age, ${ }^{9-10}$ despite European Union directives outlawing age discrimination in the workplace. ${ }^{10}$

Following the recent financial crisis there have been policy proposals in many industrialised countries to increase the age of retirement in order to reduce the burden on welfare budgets. Such plans have met with mixed reactions, despite recognition of the economic imperative. In France a proposed rise in the state retirement age from 60 to 62 has met with fierce resistance from the trade union movement and the public, angered by a loss of entitlement to the perceived benefits of retiring at 60. It is not clear whether such moves to increase default retirement ages will have positive or negative effects on the health of the elderly population. This paper presents a systematic review of the evidence of the impact of working beyond retirement on mental health, and discusses the implications for public health and welfare policy.

\section{METHODS}

The review conducted in March 2009 aimed to identify research that examined the mental health implications of working beyond retirement in older people. Published studies were identified using a search strategy developed in PubMed, and adapted for other databases including EMBASE, Cochrane, PsychINFO, AgeINFO, Cinahl, IBSS and Global Health. The search terms "depression", "anxiety" or "mental health" were combined with "retirement", "volunteering" or "employment" and "elderly or aged". A grey literature search employing the same search terms using the Google ${ }^{\mathrm{TM}}$ search engine identified a number of policy documents, but no new primary research meriting inclusion. Papers with an English title and abstract published in any language were considered. Abstracts were screened by one reviewer and rejected if it was clear that the article did not report a study of mental health in elderly people or if it was clear that the inclusion criteria were not met. The full text was obtained for 35 papers and additional articles were identified from the reference lists of these papers.

Since the 1960s, observational studies have suggested that retirees have lower morale and decreased life satisfaction than those employed. ${ }^{11,12}$ However, these studies used non-validated methods to measure morale and well-being, which are unlikely to accurately measure mental health in their study populations. In the last two decades or so, the combined use of validated depression and mental health measuring tools and multivariate analysis has improved the quality of research in this field. Articles were therefore included in this review if they were cross-sectional or longitudinal 
studies that measured the effect of paid or volunteer work beyond retirement age using a previously validated scale to measure mental health outcomes. Mental health outcomes considered for inclusion included overall mental health, depression or anxiety. In addition, we only included studies that controlled for the effect of confounding variables on mental health, such as physical health, gender and socioeconomic status.

We defined retirement age as the accepted retirement age in the country where the study took place. This is generally the age at which individuals become eligible for the state pension. We looked exclusively at studies which compared retired people and people employed over traditional retirement ages to focus specifically on the effect of working beyond the normative retirement age. We followed the Cochrane handbook guidance supporting the use of a systematic, narrative approach when meta-analysis is inappropriate due to study heterogeneity, and synthesised results by descriptive thematic analysis. ${ }^{13}$

\section{RESULTS}

Ten studies met the inclusion criteria. The characteristics of these studies are summarised in Table 1. Seven of the ten studies were cross-sectional studies and three were longitudinal studies.

\section{Cross-sectional studies}

The cross-sectional studies came from the US, ${ }^{14-16}$ Australia ${ }^{17,18}$ and Japan. ${ }^{19}$ Some studies used sample populations that were nationally representative, ${ }^{14-18}$ while others were only representative of the local community ${ }^{19,20}$ Sample sizes varied from 292 to 23,247 . Six of the seven cross-sectional studies compared paid workers to retirees ${ }^{14-19}$ and one study compared both volunteer and paid workers to retirees. ${ }^{20}$ Studies varied in how they categorised individuals as workers, volunteers or retirees. Some studies simply asked whether a person was currently retired, in paid work or volunteering and categorised them accordingly, while others looked at patterns of employment over the preceding days, months or years. Studies used various validated tools to measure mental health, depression or anxiety scores. All studies used multivariate statistical analysis to control for individual-level confounding variables such as physical health, age, gender, race, marital status and income. 


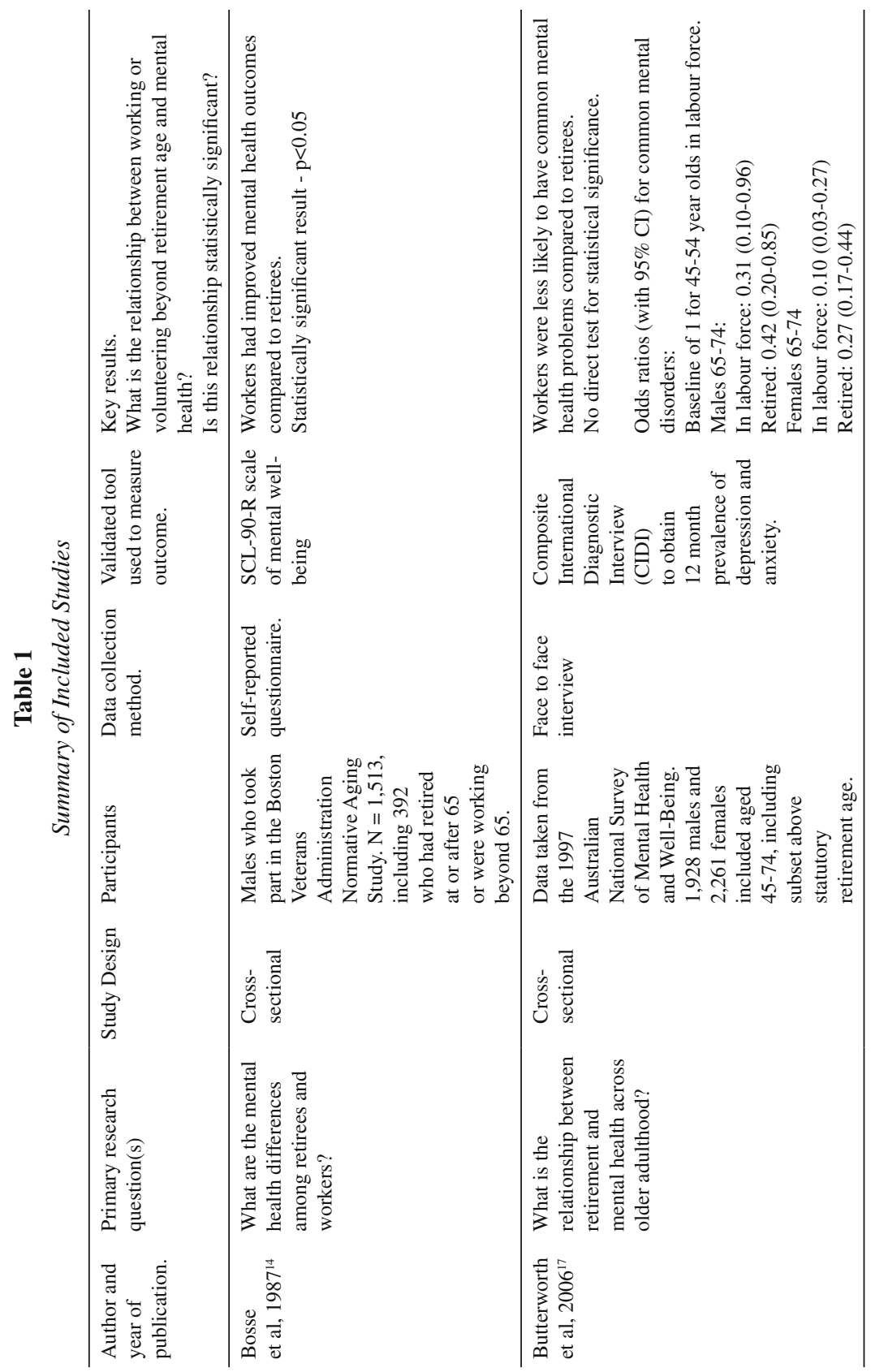




\begin{tabular}{|c|c|c|}
\hline 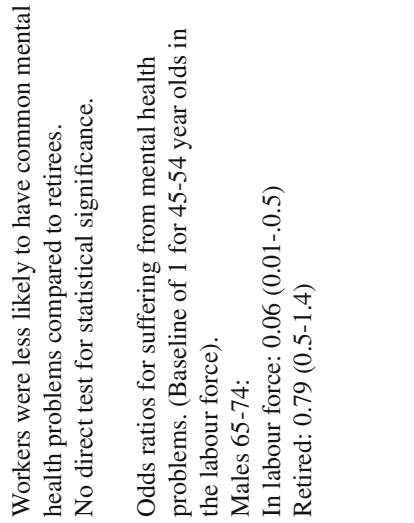 & 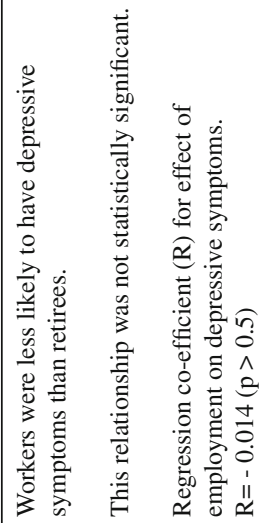 & 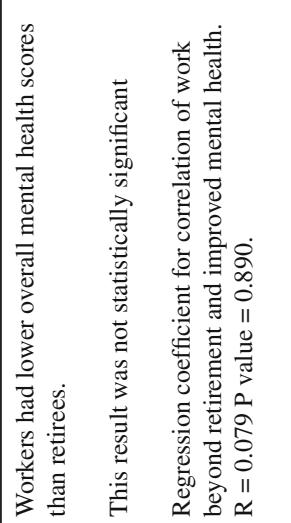 \\
\hline 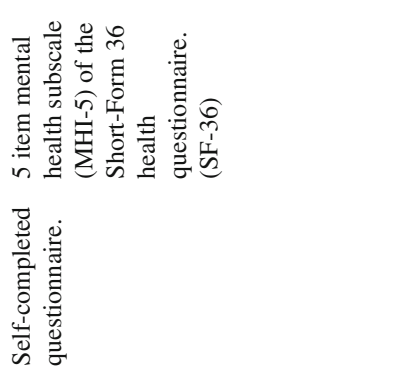 & 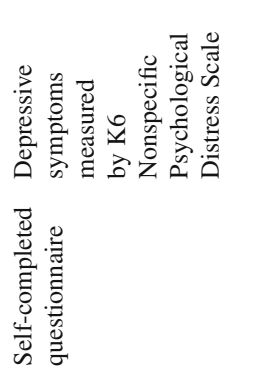 & 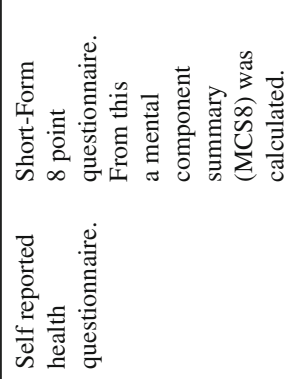 \\
\hline 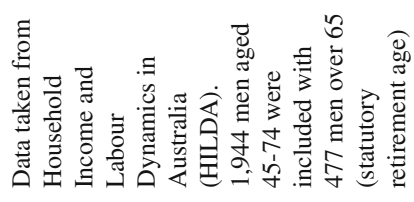 & 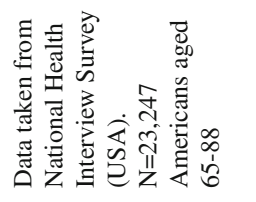 & 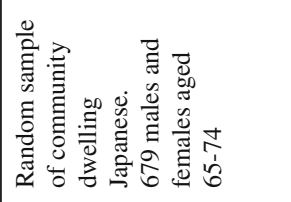 \\
\hline 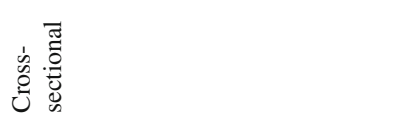 & 焉 & 吾 \\
\hline 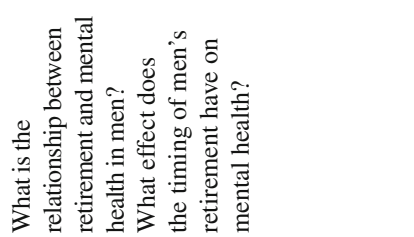 & 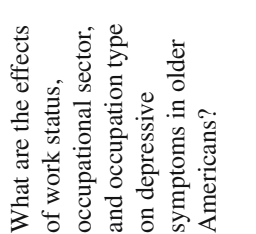 & 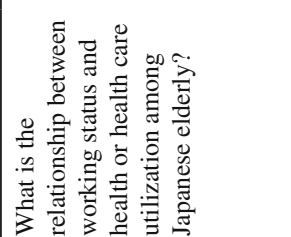 \\
\hline 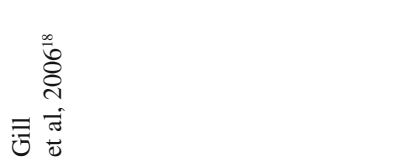 & 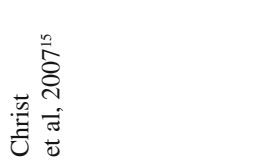 & 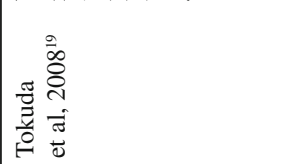 \\
\hline
\end{tabular}




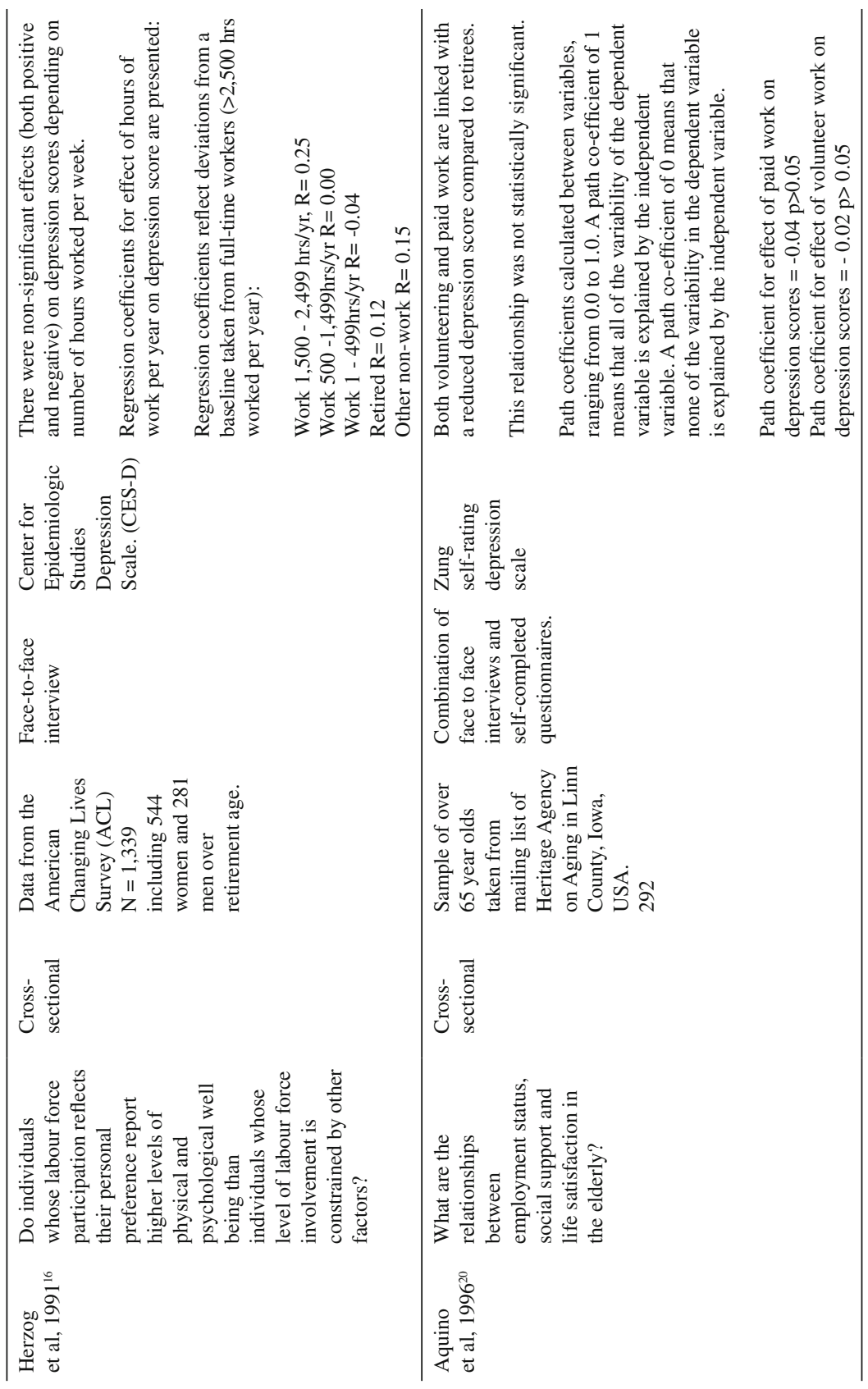




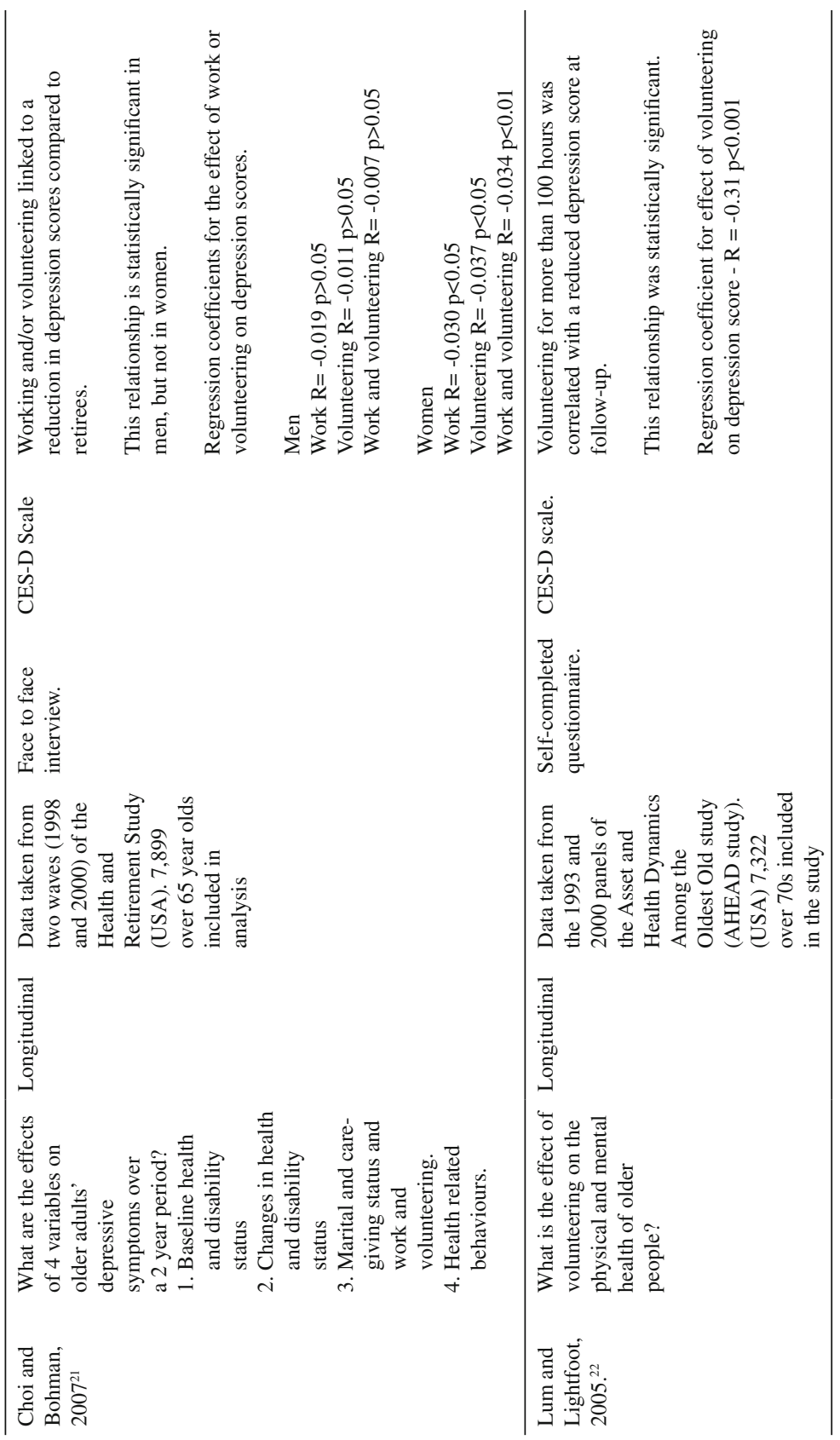




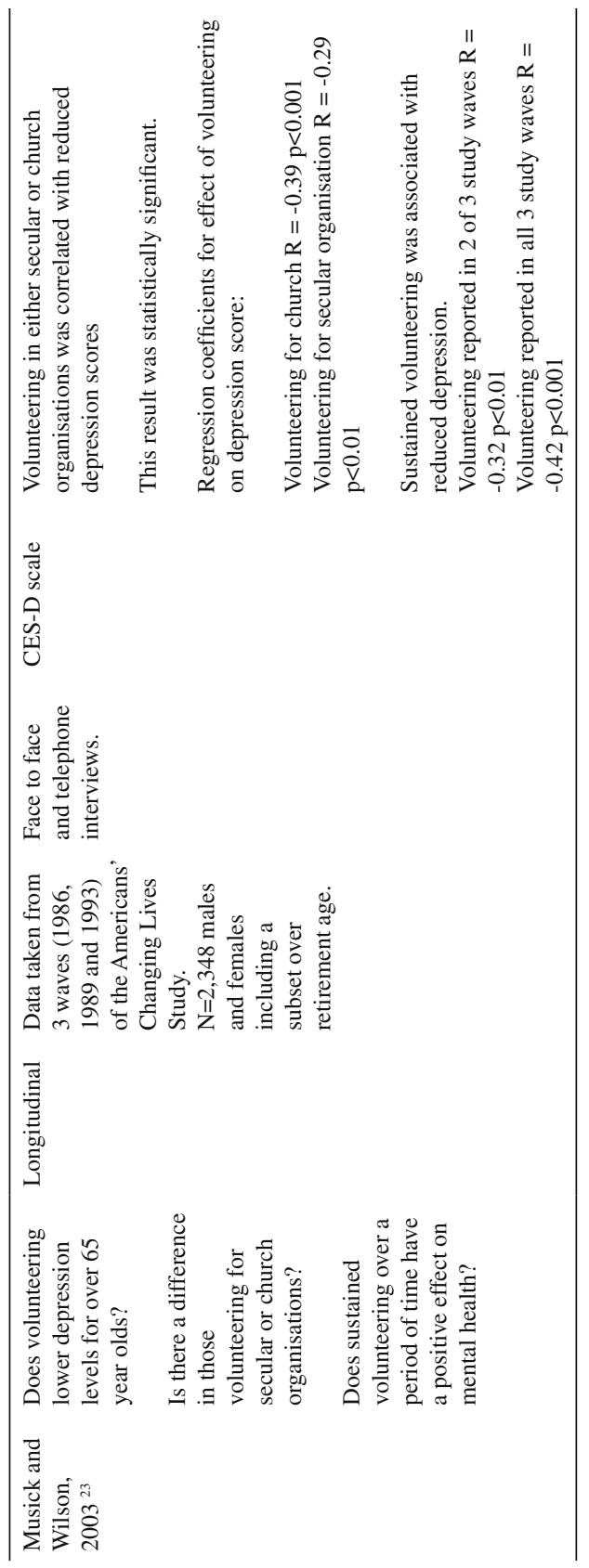


Five of the seven cross-sectional studies reported improved mental health in people who work beyond retirement age..$^{14,15,17,18,20}$ Of these five studies, one reported a significant positive association between paid or unpaid employment and improved mental well-being scores. ${ }^{14}$ Two studies reported a non-significant benefit of volunteering or paid work on mental health outcomes. Both of these studies measured self-reported depression. ${ }^{15,20}$ Two studies reported that workers experienced better mental health outcomes than retirees, but did not directly test the statistical significance of this relationship. ${ }^{17,18}$ One of these two studies used prevalence of depression and anxiety symptoms as its outcome measure ${ }^{17}$ and the other used self-reported mental health scores. ${ }^{18}$ One of the seven cross-sectional studies reported a small non-significant negative effect of work on mental health scores. ${ }^{19}$ The remaining cross-sectional study showed neither a positive nor a negative overall effect of working beyond retirement on depression scores. ${ }^{16}$

\section{Longitudinal studies}

Three of the ten studies included in the review were longitudinal studies..$^{21-23}$ All three were from the US and used a population sample that was representative of the national population. Sample sizes varied from 2,348 to 7,899 . Two of the three longitudinal studies included two waves of data, one with a seven year follow-up from the initial data sampling ${ }^{22}$ and one with two years follow-up. ${ }^{21}$ One study included three waves of data over a seven year period. ${ }^{22}$ Two of the three longitudinal studies investigated volunteer work exclusively, ${ }^{22,23}$ and one looked at the effects of both paid work and volunteer work on mental health. ${ }^{21}$ Studies varied in how they categorised individuals as workers, volunteers or retirees. In one study, for example, participants were only classified as volunteers if they had "formally" volunteered for organisations such as "The Heart Association, educational institutions, religious organisations or other such groups." 22 All three longitudinal studies used the Center for Epidemiologic Studies Depression Scale (CES-D), with data collected variously by face-to-face or telephone interview or self-reported questionnaire. Each study used multivariate statistical analysis, with controls for individual-level confounding variables.

All three longitudinal studies measured the effect of paid or volunteer work on depression scores, and all three reported significantly lower depression scores in paid or volunteer workers compared to retirees. ${ }^{21-23}$ For one of the three studies, this benefit was only statistically significant for women and not for men. ${ }^{21}$ One longitudinal study found a cumulative 
benefit of volunteer work over the follow-up period. ${ }^{23}$ In this study, individuals were interviewed at three intervals over a seven year period. Individuals who had volunteered throughout the follow-up period experienced a more pronounced reduction in depression scores than those who had volunteered sporadically.

\section{DISCUSSION}

There is growing discussion about the timing of retirement and its influence on population health. This review found that no studies showed a significant negative effect of working beyond retirement age on mental health, with four of the ten studies reporting that post-retirement employment has a statistically significant positive effect on mental health outcomes. All studies used multivariable models to analyse the effect of paid or volunteer work on mental health, controlling for the effect of individual-level confounders. Different confounding variables, such as physical health, gender, marital status, race, education status and income were analysed in different studies. The inclusion of these variables in the analysis reduced the magnitude of the positive benefits of employment on mental health..$^{15,18,19,21}$

Only one of the seven cross-sectional studies found a significant effect of employment or volunteering on mental health outcomes. The variability in the results reported by the cross-sectional studies may reflect the considerable methodological differences between them. Studies were carried out in three different countries and samples were sometimes small and not nationally representative. The studies also differed in their definitions of a worker, volunteer or a retiree and used a range of different tools and techniques to measure mental health outcomes. Cross-sectional studies are inherently limited, providing only a snapshot view of the relationship between employment and mental health and no answers as to the direction of causation in any relationship between the two variables.

In contrast, all three longitudinal studies included in the review report a significant association between voluntary or paid work and improved mental health outcomes. The longitudinal studies were more methodologically consistent than the cross-sectional studies. All the longitudinal studies were from the US, were nationally representative and all used the same tool to measure mental health outcomes.

Unlike cross-sectional studies, longitudinal studies allow conclusions to be drawn about the direction of causation in the relationship between work patterns beyond retirement and mental health. Volunteering or paid work has positive downstream effects on mental health outcomes and 
sustained volunteering throughout the post-retirement years appears to provide a greater benefit to mental health than sporadic volunteer work.

The results of the longitudinal studies reviewed here suggest that working beyond retirement age has a positive effect on mental health. The mechanisms by which continued employment may benefit mental health are likely to be complex. It has been hypothesised that factors including maintenance of productive roles, continued income and continued social support may mediate the mental health benefits. ${ }^{7,24}$ However, these factors may have varying effects on the individual depending on their preexisting lifestyle patterns, self-esteem and values. ${ }^{25}$ Mein et al. found that the impact of retirement or early retirement on the mental health of British civil servants depended on the employment grade of the civil servant. ${ }^{26}$ Those in higher employment grades actually showed improved mental health following retirement. In certain cases, retirement may improve mental health through a release from the pressure of a stressful job, or allowing the retiree to spend more time with his or her family. ${ }^{27}$ The benefits of work beyond retirement are, therefore, unlikely to be universal. One of the studies reviewed here, Herzog et al., suggests that it is freedom of choice of work rather than work in itself that is beneficial for mental health. ${ }^{16}$ Individuals who were able to choose their pattern of work had significantly better mental health than individuals who worked more or less than they wished to.

Currently, the effects of continued employment on the individual are not fully understood. Further research is required to identify which groups of individuals are most likely to benefit from continued employment beyond retirement age, and whether paid employment or volunteering is more beneficial. Additional study is also required to clarify the mechanisms by which employment or volunteering may lead to improved mental health. The longitudinal studies reviewed here, which demonstrate a link between work beyond retirement and improved mental health, have looked predominately at volunteer work and have all been carried out in the US. Further large-scale longitudinal studies need to be conducted in a wide range of national populations to confirm the beneficial effects of both volunteer work and paid employment on mental health in other industrialised countries.

\section{Policy implications}

Many European governments are aiming to raise the retirement age in an attempt to balance the ratio between employed and dependent people, as life expectancy continues to increase. The EU Lisbon strategy for growth 
and jobs, which was relaunched in 2005, ambitiously aimed to increase the average retirement age by five years to 65 and to increase labour force participation in the 55 to 64 year age group to 50 percent by $2010 .{ }^{6}$ UK government estimates suggest that adding an additional year to working lives could increase UK gross domestic product by around 2 percent. ${ }^{28}$ Our findings suggest that working beyond traditional retirement ages may be beneficial for mental health. Allowing older people free access to the employment market is likely to reduce overall mental health morbidity and mortality, while also leading to economic benefits, through a reduced burden on both health services and on the welfare state.

Policy to tackle age discrimination in the workplace will be an important step to attaining these public health and economic benefits. Currently, in the UK, France and the Netherlands, employers can opt to terminate an individual's employment when they reach the mandatory retirement age. A 2000 EU directive obliges all member states to enact anti-discrimination legislation, including discrimination on the grounds of age, ${ }^{9}$ which should make it more difficult for older employees to be forced out of work. ${ }^{29}$

Any health benefits of working beyond retirement will vary between individuals. Policies that enforce increases in the retirement age such as those proposed in the UK and France may also have harmful impacts on mental health. A recent French occupational cohort study, published after this review was conducted, showed that early retirement did not change the risk of major chronic diseases but was associated with a substantial reduction in mental and physical fatigue and depressive symptoms, particularly among people with chronic diseases.$^{30}$ For certain individuals, retirement may improve mental health by, for example, reducing workplacerelated stress or increasing leisure time.

It is, therefore, important to understand why some people want or need to continue to work, and why others do not and the impact of personal choice on any mental health benefits of extending working lives. The range of reasons why people leave the job market before reaching the age at which they could benefit from official state pension varies and will depend on physical health and disability as well as economic factors. Obviously there are socioeconomic inequalities as some people can choose to retire because they have amassed enough money to live comfortably in retirement. However, employment, welfare and health policies also need to take account of older individuals who leave employment for other reasons, with many moving to long-term sickness, unemployment or other welfare benefits. ${ }^{6}$ Research in the UK indicates that only about a third of those leaving work early do so voluntarily with approximately half remaining 
mainly dependent on state benefits. ${ }^{28}$ If the retirement age is raised to reduce this dependence on welfare budgets, both governments and the private sector will need to ensure that working conditions are improved and job activities adapted to the capabilities of ageing workers, especially for those with chronic diseases.

Whether people choose to retire from paid employment or not, our findings suggest that it is not only paid work, but also volunteer work, which can have positive effects on the mental health of elderly people. Health and social welfare policies should also include greater opportunities for older people to take part in voluntary work.

The economic and social impact of ageing populations in Europe, the US and other industrialised countries is likely to mean that retirement ages will be raised in many countries in the near future. Although our research shows that working beyond retirement can have mental health benefits, flexible retirement policies are needed to ensure that any economic policy to increase statutory retirement age does not increase health and social inequalities in the elderly.

\section{Acronyms list:}

DALYs $=$ Disability-adjusted life years

\section{Terms and definitions list:}

Retirement age: Age at which individuals become eligible for the state pension in their country of residence.

\section{Key Points:}

- Depressive symptoms are common in elderly populations.

- It has been hypothesised that retirement may have a negative effect on mental health.

- Ten studies were identified that examined the effect of working or volunteering beyond traditional retirement ages on mental health.

- Four of ten studies reported a significant positive effect of working or volunteering beyond retirement age on mental health.

- No studies reported a significant negative effect of working or volunteering beyond retirement age on mental health.

- Allowing older people free access to the labour market is likely to reduce morbidity and mortality from mental health in the elderly population.

- Policy to tackle age discrimination in the workplace will be an important step to attaining the health benefits of ongoing participation in the labour market.

- It is unclear how recently proposed policies to enforce increases in statutory retirement age will impact on population mental health, but they may increase health inequalities.

\section{Future Issues List:}

- Are there certain groups of people who are more likely to benefit from continued employment beyond retirement age? 
- Is volunteering or paid work more beneficial for mental health in older people?

- Do people who are compelled to work beyond retirement out of financial necessity have the same mental health benefits as people who continue to work beyond retirement age without financial pressures?

- What are the mechanisms by which employment or volunteering may lead to improved mental health?

Conflicts of Interest: None declared.

\section{REFERENCES}

1. Buka SL. Psychiatric epidemiology: reducing the global burden of mental health. Am J Epidemiol. 2008;168:977-79.

2. Djernes JK. Prevalence and predictors of depression in populations of elderly: A review. Acta Psychiatrica Scandinavica. 2006;113:372-87.

3. Kung HC, Hoyert DL, Xu J, Murphy SL. Deaths: Final data for 2005. Natl Vital Stat Rep. 2008;56:1-120.

4. Waern M, Rubenowitz E, Runeson B, Skoog I, Wilhelmson K, Allebeck P. Burden of illness and suicide in elderly people: Case-control study. BMJ. 2002;324:1355.

5. de Boer AG, Wijker W, de Haes HC. Predictors of health care utilization in the chronically ill: A review of the literature. Health Policy. 1997;42:101-15.

6. Doyle Y, McKee M, Rechel B, Grundy E. Meeting the challenge of population ageing. BMJ. 2009;339:b3926.

7. Portnoi VA. Postretirement depression: Myth or reality. Compr Ther. 1983; 9:31-7.

8. Cohen GD. Prospects for mental health and aging. In: Birren JE, Sloane (Editors). Handbook of mental health and Aging. Hemel Hempstead: Prentice/Hall International; 1980. p. 971-93.

9. United Kingdom. The Employment Equality (Age) Regulations 2006. 2006. Available from URL: http://www.legislation.gov.uk/uksi/2006/1031/ contents/made (Accessed 9 February 2011).

10. O'Cinneide C. Age discrimination and European Law. 2005. Employment and Social Affairs, European Commission. Available from URL: http://www. equalrightstrust.org/ertdocumentbank/age\%20discrimination $\% 20$ and $\% 20$ european\%20law.pdf (Accessed 9 February 2011).

11. Back K, WaG CS. Retirement and self-ratings. In: Simpson IH, McKinney JC, (Editors). Social aspects of aging: Durham (NC): Duke University Press; 1966. p. 120-29.

12. Kimmel DC, Price KF, Walker JW. Retirement choice and retirement satisfaction. J Gerontol. 1978;33:575-85.

13. Higgins JPT. Cochrane handbook for systematic reviews of interventions. Version 5.0.2 The Cochrane Collaboration. 2009. Available from URL: http:// www.cochrane.org/training/cochrane-handbook (Accessed 9 February 2011). 
14. Bosse R, Aldwin CM, Levenson MR, Ekerdt DJ. Mental health differences among retirees and workers: findings from the Normative Aging Study. Psychol Aging. 1987;2:383-9.

15. Christ SL, Lee DJ, Fleming LE, LeBlanc WG, Arheart KL, Chung-Bridges K, et al. Employment and occupation effects on depressive symptoms in older Americans: Does working past age 65 protect against depression? J Gerontol B Psychol Sci Soc Sci. 2007;6:S399-S403.

16. Herzog A, House JS, Morgan JN. Relation of work and retirement to health and well-being in older age. Psychol Aging 1991;6:202-11.

17. Butterworth P, Gill SC, Rodgers B, Anstey KJ, Villamil E, Melzer D. Retirement and mental health: Analysis of the Australian national survey of mental health and well-being. Soc Sci Med. 2006;62:1179-91.

18. Gill SC, Butterworth P, Rodgers B, Anstey KJ, Villamil E, Melzer D. Mental health and the timing of Men's retirement. Soc Psychiatry Psychiatr Epidemiol. 2006;41:515-22.

19. Tokuda Y, Ohde S, Takahashi O, Shakudo M, Yanai H, Shimbo T, et al. Relationships between working status and health or health-care utilization among Japanese elderly. Geriatr Gerontol Int 2008;8:32-40.

20. Aquino JA, Russell DW, Cutrona CE, Altmaier EM. Employment status, social support, and life satisfaction among the elderly. J Counseling Psychol. 1996;43:480-89.

21. Choi NG, Bohman TM. Predicting the changes in depressive symptomatology in later life: How much do changes in health status, marital and caregiving status, work and volunteering, and health-related behaviors contribute? J Aging Health. 2007;19:152-77.

22. Lum TY, Lightfoot E. The effects of volunteering on the physical and mental health of older people. Res Aging. 2005;27:31-55.

23. Musick MA, Wilson J. Volunteering and depression: The role of psychological and social resources in different age groups. Soc Sci Med. 2003;56:259-69.

24. Warr P, Butcher V, Robertson I, Callinan M. Older people's well-being as a function of employment, retirement, environmental characteristics and role preference. Br J Psychol. 2004;95:297-324.

25. Atchley RC. A continuity theory of normal aging. Gerontologist. 1989;29:183-90.

26. Mein G, Martikainen P, Hemingway H, Stansfeld S, Marmot M. Is retirement good or bad for mental and physical health functioning? Whitehall II longitudinal study of civil servants. J Epidemiol Comm Health. 2003;57:46-49.

27. Reitzes DC, Mutran EJ, Fernandez ME. Does retirement hurt well-being? Factors influencing self-esteem and depression among retirees and workers. Gerontologist. 1996;36:649-56.

28. H M Government. Building a society for all ages. London. 2009. HM Government. Available from URL: http://webarchive.nationalarchives.gov. uk/20100210151716/hmg.gov.uk/buildingasocietyforallages.aspx (Accessed 9 February 2011). 
29. Humphrey A, Costigan P Pickering K, Stratford N, Barnes M. Factors affecting the labour market participation of older workers. 2003. London: Department of Work and Pensions. Available from URL: http://research.dwp.gov.uk/asd/ asd5/rports2003-2004/rrep200.pdf (Accessed 9 February 2011).

30. Westerlund H, Vahtera J, Ferrie JE, Singh-Manoux A, Pentti J, Melchior M, et al. Effect of retirement on major chronic conditions and fatigue: French GAZEL occupational cohort study. BMJ. 2010;341:(c6149). 